\title{
Mind, body and intelligence
}

\section{This year's BBC Reith lectures are arresting and provocative but also representative of the kind of argument that gives philosophers a poor reputation in research laboratories.}

CAN machines think? And if so, in what sense? Those are two of the simple questions with which Professor John Searle of the University of California has been startling the British Broadcasting Corporation $(B B C)$ 's audiences in the past few weeks. Professor Searle is this year's Reith lecturer, which means that he is one of a long line of distinguished scholars licensed to talk at British audiences for half an hour on each of six consecutive weeks. To judge from the first four of these occasions, Professor Searle is an iconoclast in the literal sense, one concerned with the destruction of idols. And there is no reason to think the worse of him on that account. But on this occasion he may have chosen too many idols, in too breathless a rush of broadcasting time, to satisfy the intellectual curiosity of his listeners.

Searle's general title is arresting Minds, brains and science. His announced objective is to explore the relationship between the concepts of mind and body as illuminated by what has been learned of neurophysiology in recent years with the particular intention of trying to make sense of concepts such as free will, or "intentionality" as he puts it. And certainly it is an important question to answer, how to reconcile the behaviourists' view of people as predetermined exemplars of the laws of mechanics with the illusion we all share that in some sense we are in charge of our own destiny, or of events around us. Or, more accurately, where is the line to be drawn between the domains of conditioned and voluntary behaviour? And how fuzzy is that line?

We shall have to wait to see how Searle comes out on these questions. One striking measure of his success so far, however, is that he has made some of the subsidiary questions with which he has dealt into cocktail-party conversation. Is it, for example, true, as Searle asserted in the first of his lectures, that there is no serious problem about the distinction between mind and body? Body means a collection of neurones and mind means the qualities of consciousness, intentionality and so on that we attribute to ourselves. Searle's answer is that neurones are to be likened to the atoms that constitute physical objects, and that mind is the consequence of putting them together as they are in people, in every way the analogue of the external shape of the object concerned.

All this is unexceptional, even if it does not say much about the nature of the attri- butes of the macroscopic representation, the nature of consciousness, for example. No doubt even philosophers will think Searle's answer a little over-simple, but it is no less arresting on that account. The circumstance that it leaves the question of how consciousness springs from the human nervous system to be answered by the neurophysiologists is neither surprising nor unwelcome, for the question is interesting and important.

The more serious difficulty with Searle's iconoclasm so far is that he seems to have chosen for attack some idols that are conspicuous by being insubstantial, which is where the question arises of whether machines can think. In a nutshell, Searle has been tempted into the sport of making fun of the community of computer-people who believe their creations are capable of artificial intelligence, or Al as they call it. As everybody knows, it is an easy sport, like shooting sitting ducks. It is also a misguided sport, certain with a British audience to evoke smug declarations that it has been clear all along that artificial intelligence is unreal.

Searle has made his point by means of a memorable example, one much talked about as irrefutable. Put a man in an empty room but provide him with a set of rules for combining Chinese ideograms together in ways that make sense (to Chinese speakers). Then imagine that a number of Chinese speakers outside the room are able to enter bundles of ideograms which the man must combine together according to the rules provided. To those outside the room, the man may well (when he is well practised at his task) be performing like an intelligent machine. But to the man, the process will be devoid of meaning. In this setting, Searle says, the system of $\mathrm{man} /$ room is exactly equivalent to a digital computer. If the people outside have omitted some essential rules, the system will be an unintelligent computer system.

The analogy is good because it is arresting and because it is also susceptible to further analysis. The difference between the man in the Chinese room and an intelligent human being, Searle says, is that the former has been provided merely with the formal syntax of the language with which he is working - the rules for telling how symbols should be combined - but that human beings have learned to attach meaning to the symbols. Semantics are an essential part of the intelligent manipulation of language.
Careful listeners to what Searle has been saying will recognize some important qualifications of what appears to be his case, that machines cannot think in the true sense of the word. First, he says, his conclusion applies to digital computers, not all machines; an artefact that exactly simulates a human being would be able to think well enough. Second, he acknowledges that the Chinese room is devoid of senses for inferring meaning from the outside world, so that it is bound to be semantically bereft. Unfortunately, having launched his commentary on the problem of the Chinese room by teasing the prophets of artificial intelligence for their frequent overoptimistic statements of the potential of their machines, he will have left his listeners with the impression that no machine can think.

Many of Searle's listeners will have been reminded of other such essays, perhaps that eleven years ago in which Sir James Lighthill, on a commission from the Science Research Council, concluded that the claims then being made (chiefly at the University of Edinburgh) on behalf of artificial intelligence were either schemes for making machine computation capable of more complicated tasks or schemes for the further automation of mechanical process. There were no proposals, said Lighthill, for bridging the gap - whereupon the research council turned its stoniest face towards grant-proposals in this field, setting back an interesting area of research for the best part of a decade.

Searle's distinction between syntax and semantics is helpful as far as it goes, but that, unfortunately, is not very far. It creates but does not bridge a gap. The snide riposte to the implied jibe that the Chinese room is necessarily stupid is to ask what would happen if the man inside were smart enough to figure out what all those ideograms really meant. The truth is that there is a gap, but one that is already narrower than when the Lighthill report appeared eleven years ago. And the purpose in seeking to fill the gap is not to replace people by machines (because, cost apart, people are more adaptive to changing circumstances than machines) but to understand better how people function (and, perhaps, to improve the automation of processes as a by-product). To fail to acknowledge this is what gives philosophers a bad name with people at the bench. Let us hope that Searle does better when he comes to free will. John Maddox 